\title{
Simulated Analysis of Exclusive Bus Lanes on Expressways: Case Study in Beijing, China
}

\author{
Lin Zhu, Beijing Jiaotong University \\ Lei Yu, Ph.D., P.E., Texas Southern University \\ Xu-Mei Chen, Ph.D., Beijing Jiaotong University \\ Ji-Fu Guo, Beijing Transportation Research Center
}

\begin{abstract}
Deploying exclusive bus lanes is considered an important strategy for supporting public transit priority policy. This paper uses a simulation approach to evaluate planned exclusive bus lanes on expressways in Beijing, China. Two scenarios for deploying exclusive bus lanes-a curbside bus lane scenario and a median bus lane scenario-were designed. Then, a micro-simulation network platform using VISSIM was established and calibrated, with all relative errors between the simulated timevarying speeds and the field speeds less than 15 percent. Afterwards, the two bus lane scenarios were simulated, evaluated, and subsequently compared with current traffic conditions without bus lanes. It was found that for both the mainline and the whole network, the operational efficiencies of buses, general traffic, and all mixed traffic are improved with the deployment of exclusive bus lanes. Further, the median bus lane scenario slightly outperforms the curbside bus lane scenario in this case.
\end{abstract}

\section{Introduction}

As of April 2012, the number of motor vehicles in Beijing, China, was about 5.06 million. The increasing number of vehicles has resulted in many problems, such as traffic congestion, increased emissions, and noise. Improving public traffic is a key 
strategy for solving traffic problems and has received increased attention from various government agencies in Beijing. Employing exclusive bus lanes is also a basic public transit priority. The basic idea of deploying exclusive bus lanes is to accommodate large travel demands and improve urban traffic operational efficiency by implementing the proper allocation of space and time resources between buses and general traffic (Yang and Ma 1997). In 1997, Beijing installed its first exclusive bus lane on the right curbside lane of Chang'an Street, which is used only by buses from 6 AM to 8 PM. Construction of bus lanes in Beijing is quite slow, and only about 20 bus lanes are built each year. Until now, the total length of exclusive bus lanes was about 303 kilometers in Beijing, which is far from the requests of public transit planning and management. Therefore, in the 12th five-year plan of Beijing, more than 150 exclusive bus lanes will be built.

Expressways are the major arterials in the urban traffic network of Beijing, carrying more than 50 percent of the total daily traffic of the city. Traffic conditions on expressways in Beijing indicate that there are extremely high traffic volumes, a high density of public transit lines, large bus flows at bus stops, and high densities at on- and off-ramps. A commonly-observed phenomenon is that, to get through the already-congested roads, automobiles and buses must compete for the rightof-way without concessions, resulting in even worse traffic conditions. Therefore, relevant agencies are proposing to deploy exclusive bus lanes on expressways to reduce conflicts between vehicles by physically separating automobiles and buses. However, exclusive bus lanes are usually constructed on urban arterials and other key roads of general grades, and employing exclusive bus lanes on expressways is less common.

There is no doubt that exclusive bus lanes will have some degree of impact on road traffic, which has been studied by a number of researchers. Based on simulations and field surveys, St. Jacques and Levinson (1997) developed an analysis procedure for estimating capacities and speeds on arterials with at least one exclusive bus lane with either no, partial, or exclusive use of the adjacent lane. Siddique and Khan (2006) used NETSIM to model and forecast traffic conditions along BRT corridors in Ottawa for 2021, which were compared with traffic conditions in 2001. The study focused on the capacity analysis of BRT operation on exclusive bus lanes.

Although the deployment of exclusive bus lanes on expressways has been planned, relevant studies are still rare. Chen et al. (2009) analyzed the impacts of exclusive bus lanes on the capacity of the ring-road expressway using the VISSIM model. The analyzed parameters included the styles and distances of ramps, length of weaving 
sections, bus headway, and others. The simulation results showed that weaving section length and bus headway are more sensitive, especially for on- and off-ramps for curbside bus lanes.

In light of the above, the research in this paper simulated the impact of deploying exclusive bus lanes on an expressway. To this end, it first carried out a series of comprehensive traffic surveys and data collections along the Western 3rd Ring-Road Expressway in Beijing. Second, it explained the conditions of setting an exclusive bus lane and designed two bus lane scenarios, including a median bus lane and a curbside bus lane. Then, it established a simulation platform using VISSIM for the Western 3rd Ring-Road Expressway and calibrated the model parameters. Finally, it comparatively simulated and evaluated the two designed scenarios of an exclusive bus lane.

\section{Study Area and Data Collection}

\section{Description of Western 3rd Ring-Road Expressway}

Existing ring-road expressways in Beijing include the 2nd, 3rd, 4th, 5th, and 6th ringroad expressways. The selected network in this study is the main portion of the Western 3rd Ring-Road Expressway Network, which is about 8.5 kilometers long in the south-north direction, including 7 interchange bridges, as shown in Figure 1. The Western 3rd Ring-Road Expressway provides 3 lanes in each direction with widths of 3.5 meters, 3.25 meters, and 3.5 meters for median, center, and shoulder lanes, respectively, as well as an emergency lane that is 4.75 meters wide. There are frontage roads present with two lanes in each direction along the expressway, which are connected to the mainline through ramps. A green zone with a width of 2 meters is reserved in the middle of two directions as well as between the mainline and frontage roads.

One of the busiest traffic corridors in Beijing, the Western 3rd Ring-Road Expressway is crossed by four urban expressways and four major arterials. Along and near the expressway, there exist Lize Bridge Coach Station, Liuli Bridge Coach Station, Lianghuachi Coach Station, and Beijing Western Railway Station, the largest railway station in Beijing. Public transit demand is quite high in this area, with a total of more than 40,000 passengers per day getting on and off buses at each bus stop. The bus cross-sectional volume in the peak hours reaches 300 vehicles per hour, including 12- or 14-meter single buses; articulated buses 14,16 or 18 meters in length; and 10- or 12-meter double-deck buses. Thus, many large vehicles run on 
the expressway simultaneously, which considerably affects the traffic conditions on the expressway.

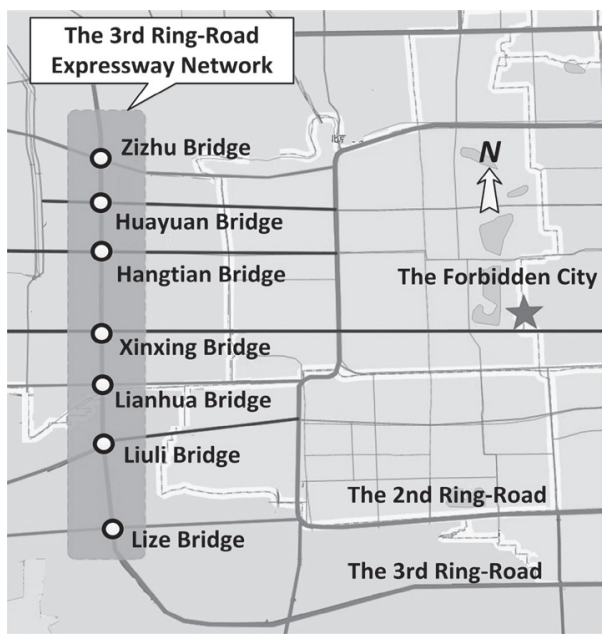

\section{Figure 1. Location of Western 3rd Ring-Road Expressway Network in Beijing}

\section{Data Collection and Preparation}

Using data sources, collection methods, and data characteristics and usage, this study carried out four tasks of data collection to support the research.

The first task was collecting geographical data, such as the latest version of the Beijing E-map and aerial map, the regional road GIS map, and the transit route GIS map, which provided the geographic and structure information about the network.

The second task was collecting information about network facilities and traffic control measures, including road geometric information (length, width, and number of lanes), locations of on- and off-ramps, traffic paths at intersections and overpasses, intersection signal timings, and information about bus stops (location, form, length of platform, and number of berths) and distribution of transit routes.

The third task was collecting traffic flow data at network entrances and diversion points, which are required by the simulation model. Specifically, the data contain flows at 30 network entrances, diversion flow ratios at 45 ramps, traffic volumes at 8 approaches of 2 signalized intersections and 78 diversion points of 7 overpasses, and bus headways of each bus line at the entrances. 
The final part task collecting data from Remote Traffic Microwave Sensors (RTMS) and the transit data from Global Position System (GPS). RTMS data can provide flow and speed information at 20 sections along the Western 3rd Ring-Road Expressway. The original data collected at 2-minute intervals by RTMS were aggregated into data at time intervals of 10 minutes, 1 hour, or 2 hours. In the study, hand-carried GPS units were used to collect bus speed data at 2-second intervals for selected bus lines by boarding on buses. These data were used in the calibration and validation of the simulation model.

\section{Design of Exclusive Bus Lanes on Expressways}

\section{Conditions of Setting an Exclusive Bus Lane}

This section explains the conditions of setting an exclusive bus lane, as follows:

(1) Geometric conditions on the road: There should be at least 2 lanes in each direction on the road, and it is better if there are 3 or 4 lanes (Lu 2003). Considering the needed space for bus vehicles, the width of a bus lane usually equals 3.5 meters, which can be appropriately reduced but should be at least 3 meters (Yang 2003). The Western 3rd Ring-Road Expressway has 3 lanes in each direction with widths of 3.5 meters, 3.25 meters, and 3.5 meter, respectively, and an emergency lane that is 4.75 meters wide. Accordingly, the geometric structure of the Western 3rd Ring-Road Expressway meets the physical requirements of deploying exclusive bus lanes.

(2) Traffic saturation level on the road: It is necessary to deploy an exclusive bus lane when the volume-to-capacity ratio on a road arrives at or exceeds the value of 0.8 (Zhang et al. 2000). According to the surveyed flow data, the average volume-to-capacity ratio on the Western 3rd Ring-Road Expressway is 0.94 , and the values of several sections are higher than 1 .

(3) Bus volume on the road section: It is suggested to build an exclusive bus lane if bus volume on a road section in peak hours is higher than 150 vehicles per hour (Yang et al. 2000). The field surveyed data indicate that the bus volume in the peak hours on the mainline of the Western 3rd Ring-Road Expressway is more than 225 vehicles per hour.

(4) Public transit passenger volume on the road section: The Highway Capacity Manual (National Research Council 2000) suggests that passenger volume on a bus lane should be 50 percent higher than that on other lanes, and this value should be more than 3,000 person-trips per hour on the planned 
bus lane in Shanghai (Lin et al. 2007). According to the surveyed data, the average passenger volume of public transit on the Western 3rd Ring-Road Expressway is about 17,750 person-trips per hour in the peak hours and occupies about 70 percent of total service passenger volume on the section.

Consequently, it is qualified and necessary to deploy an exclusive bus lane on the Western 3rd Ring-Road Expressway in Beijing.

\section{Scenario Designs of Exclusive Bus Lane}

The key elements in the design of exclusive bus lanes on expressways include physical location of the bus lane, structure of the bus stops, ramp control towards buses, and corresponding adjustment of bus lines, all of which have been considered in the designs of the two exclusive bus lane scenarios on the Western 3rd Ring-Road Expressway. Basic on the current structure of the roads, two exclusive bus lane scenarios were designed (as shown in Figure 2), which were modeled and evaluated with the established VISSIM simulation model.

\section{Basic Scenario}

Current traffic conditions without the exclusive bus lane were simulated based on the field data collected.

\section{Scenario 1: Curbside Bus Lane Scenario}

With the road structure of the mainline unchanged, a curbside lane was used as the bus lane in this scenario. There were no major structural and positional changes on bus stops, i.e., bus bays remained the same, passenger waiting areas continued to occupy the green zone, and buses parked in the emergency lane, as shown in Figure 2. Buses ran on the curbside lane and could enter or exit the bus lane conveniently. All buses followed the current routes.

\section{Scenario 2: Median Bus Lane Scenario}

In this scenario, the median lane was used as the bus lane. Therefore, bus stops were moved from the curbside to the center of the expressway. The widths of the general traffic lanes and the emergency lane were slightly narrowed to ensure adequate space required for parking the buses. Figure 2 shows the configuration of the bus stop area in the median bus lane scenario. Buses had to enter or exit the median bus lane by crossing two general traffic lanes, which caused a serious interference with traffic. Therefore, a bus ramp control strategy was proposed, which meant that when running in the median bus lane, buses could enter the mainline only from one on-ramp and exit the mainline only from one off-ramp. In this design, bus 
Basic scenario

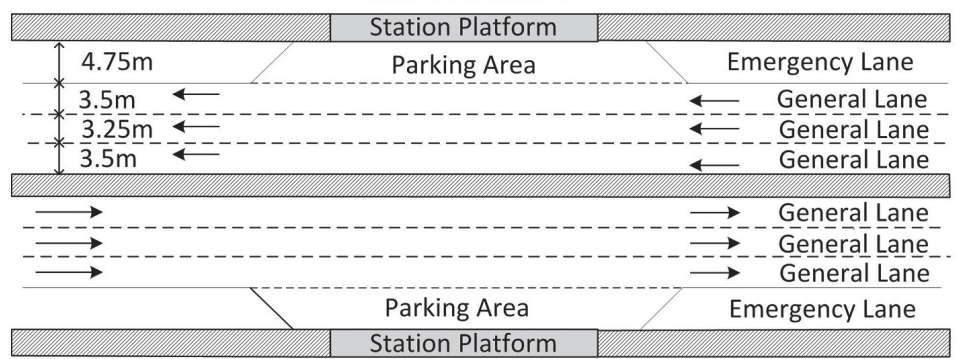

Scenario 1: Curbside bus lane scenario

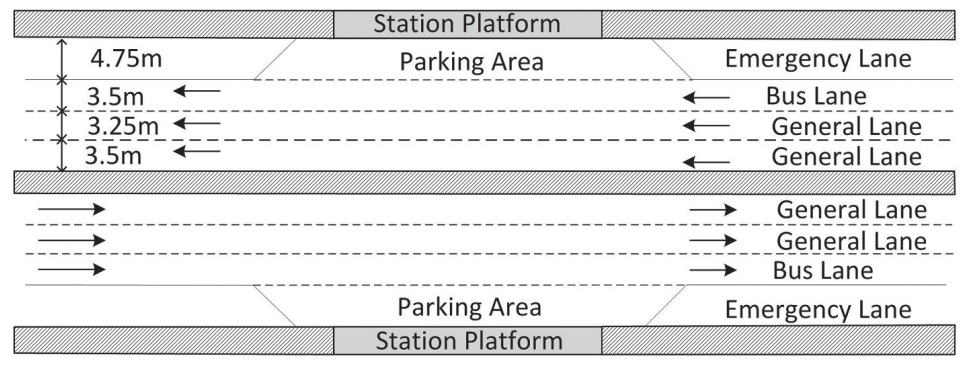

Scenario 2: Median bus lane scenario

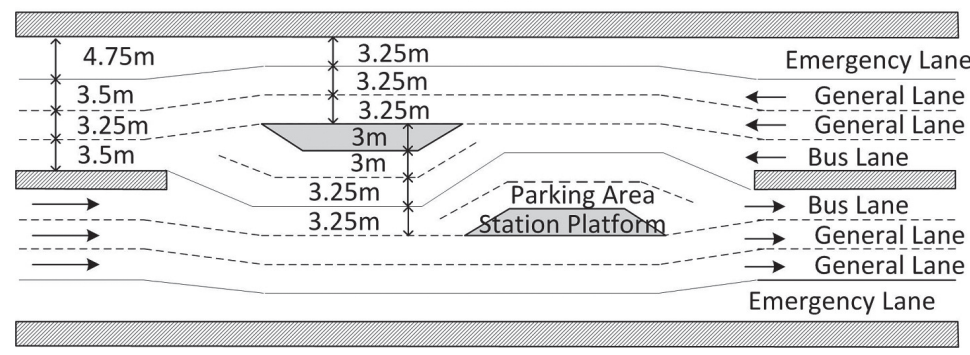

\section{Figure 2. Configuration design of bus stop area in different scenarios}

access ramps in both directions were placed at the upstream and downstream links of Lianhua Bridge. To accommodate this design, some bus lines were also adjusted correspondingly.

\section{Establishment of Simulation Model}

\section{Description of Simulation Approach}

In this study, the traffic simulation technique was used to model, evaluate, and analyze the scenarios of an exclusive bus lane on the Western 3rd Ring-Road Expressway. VISSIM, a widely used micro-simulation model, was employed. A 
simulation framework was developed using VISSIM for this study, based on the network information and traffic data of the Western 3rd Ring-Road Expressway, as shown in Figure 3.

(1) Develop a simulation platform of the Western 3rd Ring-Road Expressway Network using VISSIM based on the surveyed data.

(2) Calibrate the physical attributes of the network, the vehicle desired speed distribution using the frequency analysis, and the driving behavior parameters using a combined calibration algorithm (introduced in the next subsection).

(3) Design and run simulation scenarios, including the simulation of current traffic conditions and simulations of two different designs of the exclusive bus lane.

(4) Select a set of performance measures to analyze the simulation results and evaluate the effectiveness of different designed scenarios.

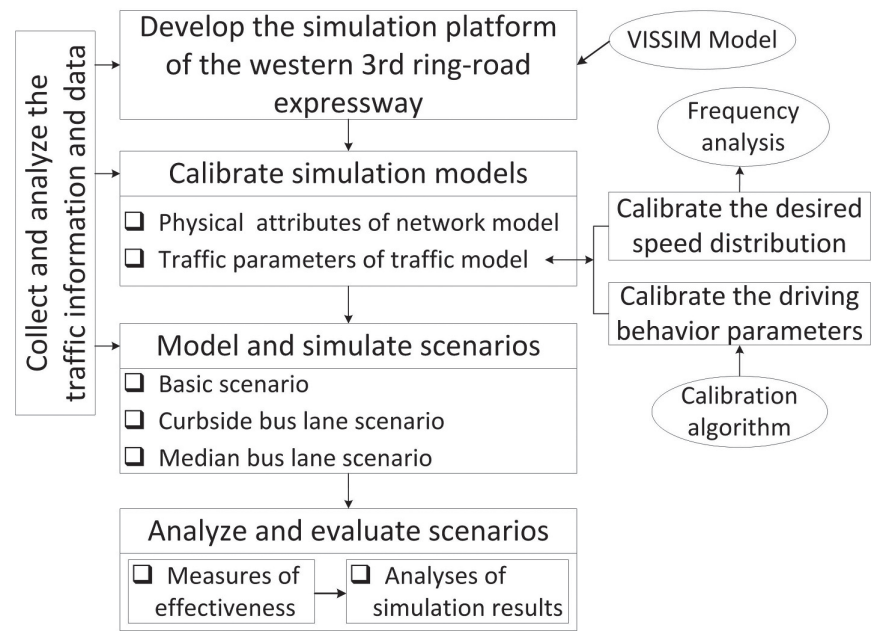

Figure 3. Flow diagram of simulation approach

\section{Calibration of Simulation Model}

Roads and vehicles are the basic elements of urban traffic systems; therefore, a traffic simulation model usually consists of a network element and a traffic element. The former describes the geometric structures of roads and the connective relations of links, while the latter describes the moving characteristics of vehicles. Consequently, the calibrations of the two aspects underlie the accuracy and reliability of scenario experiments and evaluations. 
Calibration of the network model is completed by adjusting the static traffic parameters, including the connections of links, flow paths and ratios at key nodes, and locations of functional change of lanes. The selected precision indicator for this calibration was the Relative Errors (RE) of two-hour accumulated flows from 7-9 AM between the simulated results and the collected RTMS data. The locations of detectors in the simulation model were made consistent with RTMS detectors in the real network, as shown in Figure 4. After calibrating the network model, the maximum RE of the two-hour accumulated flows was 9.00 percent. This result satisfied the requirements of the study.

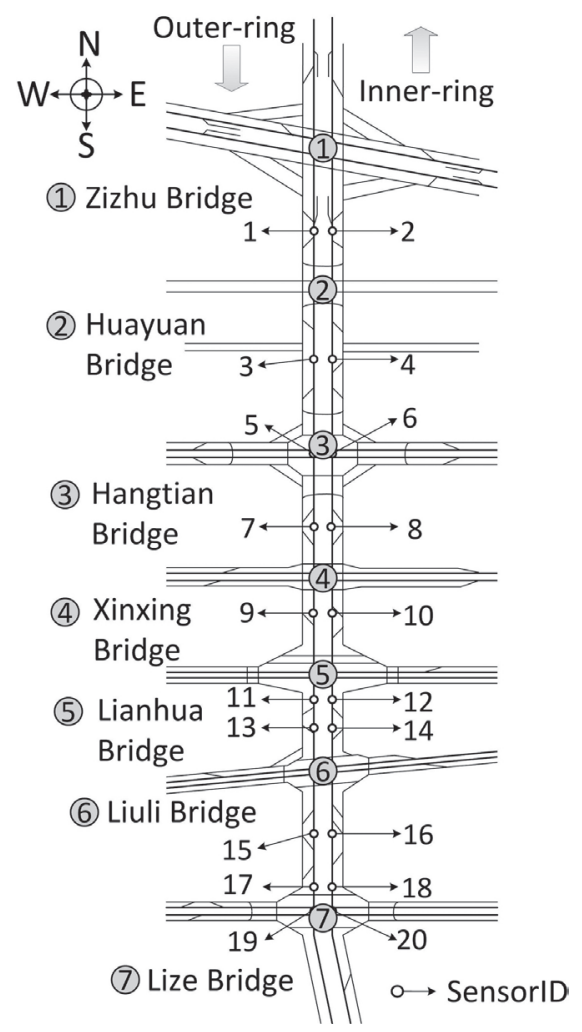

\section{Figure 4. Location of detectors along the Western 3rd Ring-Road Expressway}

Calibration of the traffic model is conducted to adjust the default model parameters to capture the actual traffic behaviors in the real network. In VISSIM, the key parameters that needed to be calibrated included the desired speed distribution and driving behavior parameters. 
In VISSIM, desired speed distribution is defined to describe the fact that a driver will travel at a desired speed (with a stochastic variation) when not hindered by other vehicles. The maximum and minimum values for the desired speed, as well as the intermediate points, are determined by a frequency analysis of the vehicle speed data collected during free-flow periods. The desired speed distribution of general traffic was obtained by analyzing the speed data from RTMS on the Western 3rd Ring-Road Expressway from 12-6 AM on October 7 and 8, 2008; the desired speed distribution of buses on general lanes was obtained by analyzing the GPS speed data of buses on the Western 3rd Ring-Road Expressway from 2-4 PM (the lowest bus-flow period). It was noted that there are no deployed bus lanes on the Western 3rd Ring-Road Expressway at present. Therefore, the GPS speed data of buses on the section from Xizhimen Bridge to Jishuitan Bridge of the 2nd ring-road from 7-9 AM were collected and analyzed to obtain the desired speed distribution of buses on the bus lane and represent the bus running condition on the bus lane on the Western 3rd Ring-Road Expressway.

In VISSIM, driving behavior parameters describe the vehicle-following and lanechanging behaviors, lateral behavior, and reaction behavior to signals. In a sensitivity analysis of parameters using a simple network, 10 driving behavior parameters were screened, including the maximum look-ahead distance, average standstill distance, additive part of safety distance, multiplicable part of safety distance, maximum deceleration for lane changes, accepted deceleration for lane changes, waiting time before diffusion, minimum headway for lane changes, reduction rate (as meters per $1 \mathrm{~m} / \mathrm{s}^{2}$ ), and minimum lateral distance for $50 \mathrm{~km} / \mathrm{h}$. Combining the Generic Algorithm (GA) with the Simultaneous Perturbation Stochastic Approximation Algorithm (SPSA), a calibration program for driving behavior parameters was developed using Visual $\mathrm{C}_{++}$and MATLAB languages. First, the parameters were locked in a relatively small area using the GA, overcoming the SPSA's shortcoming of inefficient global optimization; then, the SPSA was used to solve the problem in the locked area, overcoming the slow convergence of GA. In the calibration process, the Sum of Squared Error (SSE) between the simulated time-varying speeds and the actual speeds was selected as the measure to determine the best combination of the 10 parameters for the Western 3rd Ring-Road Expressway simulation model. The calibration algorithm is explained in detail by Chen et al. (2011). After completing the calibrations of network model and traffic model, the timevarying speeds at 10-minute intervals were output from 20 detectors, and then the simulation results were compared with the RTMS data. The simulated time-varying 
speeds and the actual RTMS speeds were plotted around the 45-degree line, as shown in Figure 5 . The relative errors of time-varying speeds at all 20 detectors in the network was less than 15 percent.

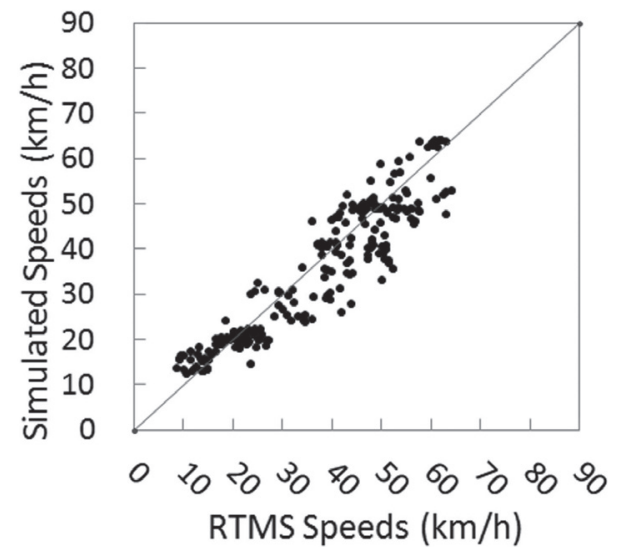

Figure 5. Comparison plots between simulated and collected time-varying speeds

\section{Measures of Effectiveness}

This study evaluated the impacts of exclusive bus lane schemes on traffic conditions on expressways using a traffic simulation model. The evaluation targets included buses, general cars, and all traffic. The whole network is composed of the Western 3rd Ring-Road Expressway, frontage roads, and crossing roads. According to different parts of the network and targets for traffic evaluation, the Measures of Effectiveness (MOEs) were selected, as listed in Table 1. All the selected MOEs focus on the efficiencies of buses, general traffic, and all traffic for evaluating bus operational impacts, economic benefits, environment effects, etc.

For the mainline of the Western 3rd Ring-Road Expressway, the average crosssectional speeds were obtained from 20 detectors at 10-minute intervals, and the average travel time was the mean travel time of all vehicles that completed travel on the mainline. For the whole network, average travel speed was equal to total distance traveled by all vehicles divided by total travel time, while average delay per unit distance was calculated by total travel delays of all vehicles divided by total travel distance. In addition, to evaluate the performance of all mixed traffic in the entire network, the numbers of passengers in buses and general vehicles were used as the weights in calculating measures. 
Table 1. MOEs for Evaluating Exclusive Bus Lane

\begin{tabular}{|l|c|c|}
\hline $\begin{array}{l}\text { Range of Network for } \\
\text { Evaluation }\end{array}$ & $\begin{array}{c}\text { Target of } \\
\text { Evaluation }\end{array}$ & Measures of Effectiveness \\
\hline \multirow{4}{*}{$\begin{array}{l}\text { Mainline of the Western } \\
\text { 3rd Ring-Road } \\
\text { Expressway }\end{array}$} & Bus & Average section speed $(\mathrm{km} / \mathrm{h})$ \\
\cline { 2 - 3 } & \multirow{2}{*}{ General Traffic } & Average travel time $(\mathrm{s} / \mathrm{veh})$ \\
\cline { 2 - 3 } & All traffic & Average section speed $(\mathrm{km} / \mathrm{h})$ \\
\cline { 2 - 3 } & \multirow{3}{*}{$\begin{array}{l}\text { Whole Simulation } \\
\text { Network }\end{array}$} & Average travel time $(\mathrm{s} / \mathrm{veh})$ \\
\cline { 2 - 3 } & General Traffic & Average travel time $(\mathrm{s} /$ person) \\
\cline { 2 - 3 } & & Average travel speed $(\mathrm{km} / \mathrm{h})$ \\
\cline { 2 - 3 } & All traffic & Average delay per unit distance $(\mathrm{s} / \mathrm{km})$ \\
\cline { 2 - 3 } & & Average travel speed $(\mathrm{km} / \mathrm{h})$ \\
\hline
\end{tabular}

\section{Simulations and Analyses}

Simulation runs were implemented for the designed scenarios using the established VISSIM platform for the Western 3rd Ring-Road Expressway. Traffic flows input in the basic scenario came from the field data, while those in the curbside and median bus lane scenarios were obtained from the outputs of the mesoscopic INTEGRATION model, which covers a larger area network (BJTU and BTRC 2008). The simulation period was set to three hours. The first half-hour is the warm-up time used to load the network with traffic, the last half-hour was the clear-up time used to empty the network, and the middle two hours were used to simulate the actual period of 7-9 AM.

Spatial-temporal speed distributions were generated to illustrate the impacts of exclusive bus lanes on buses and general traffic, as shown in Figures 6 and 7. In the morning peak hours, the current cross-sectional speeds of buses and general traffic in the outer-ring direction were higher than those in the inner-ring direction. Figure 6 shows that the detected bus speeds from most of detectors increased visibly after deploying the exclusive bus lanes. However, within the curbside bus lane, the speeds at Sensor 3 in the outer-ring direction were reduced as buses are interfered with by cars entering or exiting the mainline, which generated a bottleneck in the outer-ring. As shown in Figure 7, the traffic conditions on the general lanes in the two exclusive bus lane scenarios were much better than current conditions, especially in the outer-ring direction. In the median bus lane scenario, because bus 
access ramps are set near Lianhua Bridge, plus more loading traffic in the inner-ring, the traffic in the south of Lianhua Bridge remained terrible.
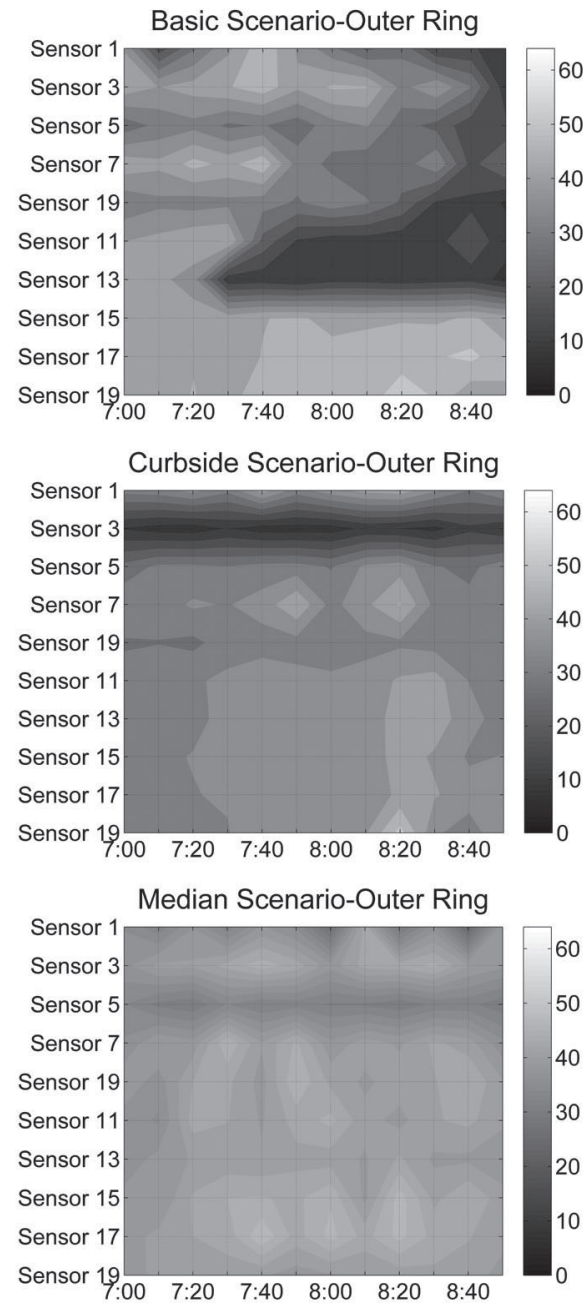
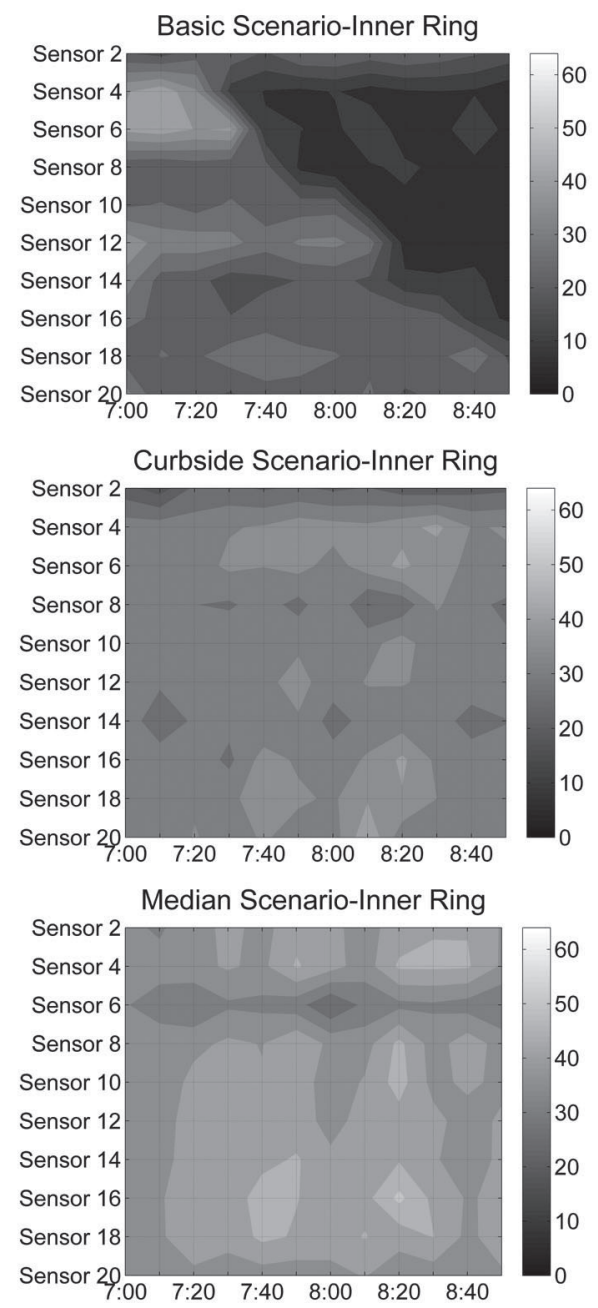

Figure 6. Spatial-temporal speeds distributions of buses 

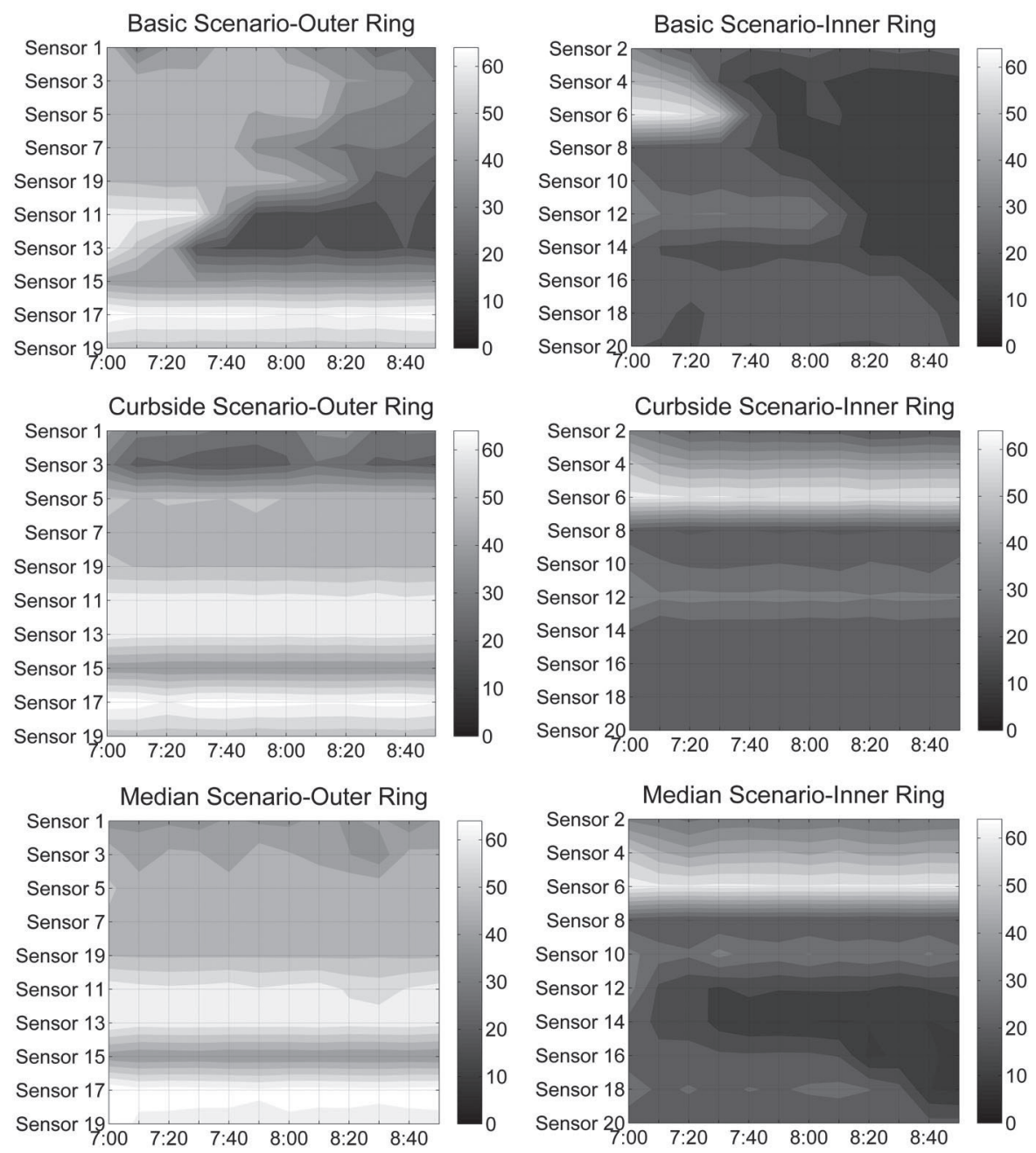

\section{Figure 7. Spatial-temporal speeds distributions of general traffic}

Figure 8 illustrates the average travel times of different vehicles completing travel on the mainline of the Western 3rd Ring-Road Expressway under the three scenarios. From Figure 8, the following conclusions can be derived:

(1) Currently, the travel time in the inner-ring direction is higher than that in the outer-ring direction, and the bus travel time is higher than the general traffic travel time. 
(2) In the median bus lane scenario, the travel times of both buses and general traffic decreased significantly.

(3) In the curbside bus lane scenario, although the right-of-way of traffic was well defined, the freedom of general traffic for entering and exiting the mainline was compromised, which increased the travel time of general traffic by 3.4 percent.

(4) The average travel times of all mixed traffic decreased in both directions with the exclusive bus lanes. Apparently, the magnitude of decrease in the median bus lane scenario is much bigger.

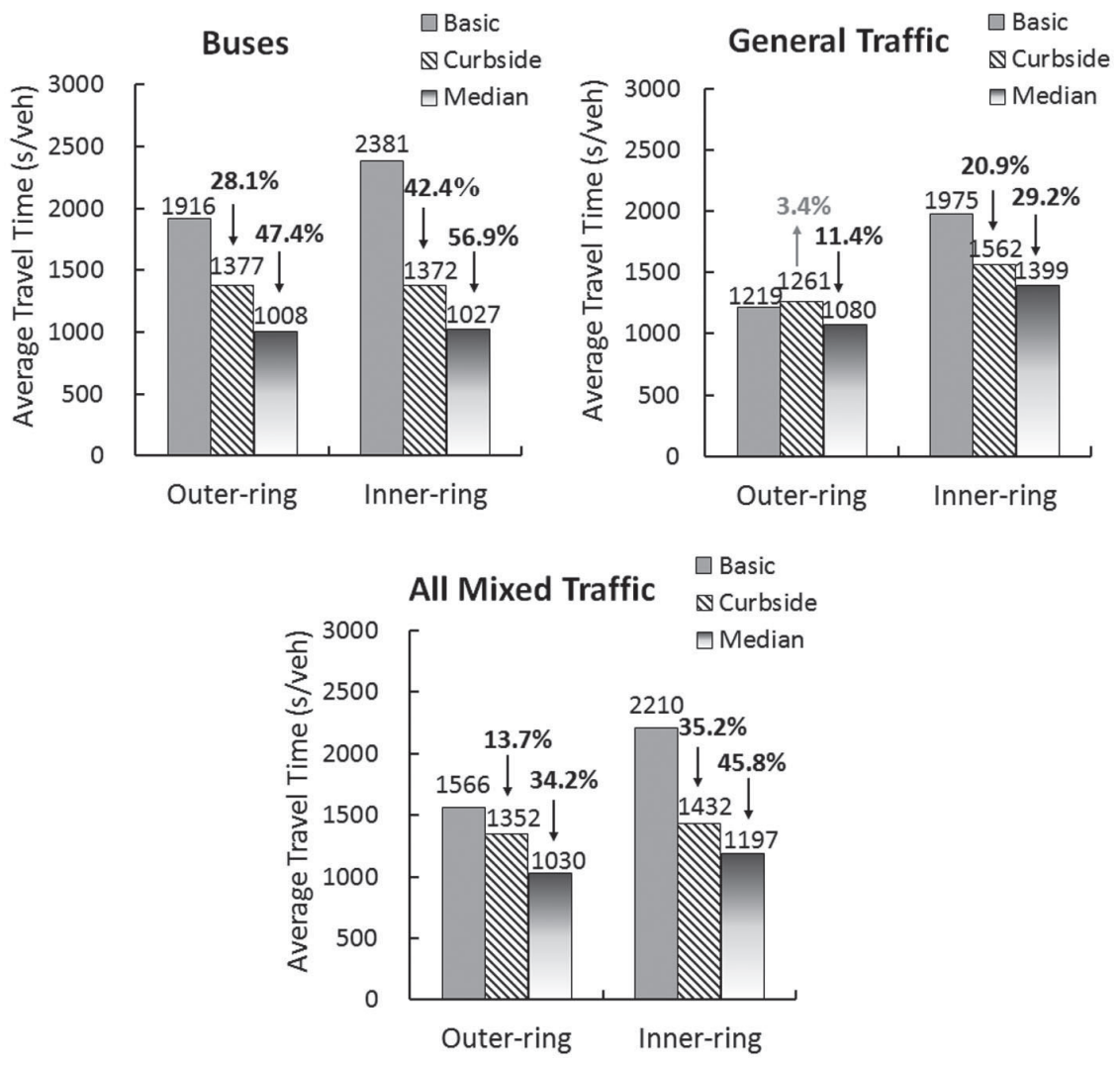

Figure 8. Average travel times of different traffic types on mainline

Impacts of the exclusive bus lane on traffic conditions of the entire studied network were analyzed. Results of MOEs are shown in Table 2. From the values of average travel speed and average delay per unit distance for all traffic in the simu- 
lation network, the median bus lane scenario outperformed the curbside bus lane scenario in this case.

Table 2. Impacts of Exclusive Bus Lane on Whole Simulation Network

\begin{tabular}{|l|l|c|c|c|c|c|}
\hline $\begin{array}{c}\text { Traffic } \\
\text { Type }\end{array}$ & \multicolumn{1}{|c|}{ Measures of Effectiveness } & \multicolumn{2}{c|}{$\begin{array}{c}\text { Basic } \\
\text { Scenario }\end{array}$} & \multicolumn{2}{c|}{$\begin{array}{c}\text { Curbside Bus } \\
\text { Lane Scenario }\end{array}$} & \multicolumn{2}{c|}{$\begin{array}{c}\text { Median Bus } \\
\text { Lane Scenario }\end{array}$} \\
\hline \multirow{2}{*}{ Bus } & Average travel speed $(\mathrm{km} / \mathrm{h})$ & 19.85 & 26.76 & $\uparrow 34.8 \%$ & 27.36 & $\uparrow 37.8 \%$ \\
\cline { 2 - 8 } & Average delay per distance $(\mathrm{s} / \mathrm{km})$ & 83 & 35 & $\downarrow 57.8 \%$ & 33 & $\downarrow 60.2 \%$ \\
\hline $\begin{array}{l}\text { General } \\
\text { Traffic }\end{array}$ & Average travel speed $(\mathrm{km} / \mathrm{h})$ & 30.94 & 34.73 & $\uparrow 12.2 \%$ & 37.37 & $\uparrow 20.8 \%$ \\
\cline { 2 - 8 } & Average delay per unit distance $(\mathrm{s} / \mathrm{km})$ & 45 & 34 & $\downarrow 24.4 \%$ & 27 & $\downarrow 40.0 \%$ \\
\hline $\begin{array}{l}\text { All Mixed } \\
\text { Traffic }\end{array}$ & $\begin{array}{l}\text { Average delay per unit distance }(\mathrm{s} / \mathrm{km} / \\
\text { person) }\end{array}$ & 62 & 35 & $\downarrow 43.5 \%$ & 30 & $\downarrow 51.6 \%$ \\
\hline
\end{tabular}

\section{Conclusions and Recommendations}

Based on the field data, this paper studied the deployment of an exclusive bus lane on the Western 3rd Ring-Road Expressway in Beijing, China. It established a simulation platform using VISSIM, calibrated the parameters of network model and traffic model, and modeled both a curbside bus lane and a median bus lane. After calculating MOEs for before and after deploying bus lanes, the findings can be summarized as follows:

(1) Apparently, in the morning peak hours, the traffic on the inner-ring of the Western 3rd Ring-Road is more congested than that on the outer-ring. The former carries more traffic volumes and experiences lower speed.

(2) For the mainline of the expressway, the average speeds of buses improve with the exclusive bus lanes, and the average travel time decreases.

(3) The spatial-temporal speeds of general traffic on the expressway have more noticeable characteristics with the deployment of exclusive bus lanes. Congestion appears mainly north of Huayuan Bridge on the outer-ring and south of Lianhua Bridge on the inner-ring.

(4) For the case network in this paper, the traffic operational efficiency of traffic in the bus lane scenarios was improved. Further, the median bus lane scenario slightly outperformed the curbside bus lane scenario.

This is the first relatively complete case study on the design and evaluation of exclusive bus lanes on urban expressways. The entire study was carried out on the 
basis of comprehensive and extensive field traffic data. Therefore, the study results are of practically significance.

Evaluations in the paper, which focus mainly on traffic impacts, are still quite general. It is recommended that further studies be conducted on the special traffic operational problems associated with the deployment of exclusive bus lanes, such as impacts on the traffic near bus stops, traffic conditions near on- and off-ramps, etc. This paper focuses only on the corridor network of the Western 3rd Ring-Road Expressway. It is, therefore, recommended that the study be expanded in the future to other networks with different locations and scopes, such as the other ring-road expressways or radial roads.

\section{Acknowledgment}

This paper was prepared based on support from Major Projects of the Beijing Transportation Research Center \#T08L04404 and \#CZ200704 and from Fundamental Research Funds for the Central Universities \#2009YJS045.

\section{References}

Beijing Jiaotong University (BJTU) and Beijing Transportation Research Center (BTRC). 2008. The Research Report of Dynamic Traffic Model for Beijing. Beijing, China.

Chen X. M., L. Yu, L. Zhu, J. F. Guo, and M. Z. Sun. 2009. Capacity analysis of weaving sections on an urban expressway with exclusive bus lanes using microscopic traffic simulation. 88th Transportation Research Board Annual Meeting CDROM, \#09-0535, Washington, D.C.

Chen X. M., L. Yu, L. Y. Zhu, Y. Zhang, and Z. Lin. 2011. Calibrating and validating a micro-simulation model of a bus rapid transit corridor with heuristic optimization methods. 90th Transportation Research Board Annual Meeting CD-ROM, \#11-2641, Washington, D.C.

Lin T., K. F. Yang, and J. X. Zheng. 2007. Study on bus lane system planning method: Case study of Shenzhen. Traffic \& Transportation 7: 1-4.

Lu J. 2003. Study of installation conditions of bus lanes. Communications Standardization 1: 59-61. 
National Research Council. 2000. Highway Capacity Manual 2000. Washington, D.C.: Transportation Research Board.

Siddique, A. J., and A. M. Khan. 2006. Microscopic simulation approach to capacity analysis of bus rapid transit corridors. Journal of Public Transportation 9: 181-200.

St. Jacques, K., and H. S. Levinson. 1997. Operational analysis of bus lanes on arterials. TCRP A-7. Washington, D.C.: Transportation Research Board, National Research Council.

Yang, X. G., and L. Ma. 1997. Design features and priority control and management on urban bus lanes. City Planning Review 3: 36-37.

Yang, X. G., G. W. Zhou, M. S. Hang, and C. H. Shi. 2000. Technologies and methods of transit priority. Urban Transport of China 2: 1-12.

Yang, X. G. 2003. Manual of Urban Traffic Design. Beijing: China Communications Press.

Zhang, W. H., Y. J. Huang, and G. Hu. 2003. Study on design standards for urban bus lanes. Communications Standardization 7: 33-36.

\section{About the Authors}

LiN ZHU (08114194@bjtu.edu.cn) is a Ph.D. Candidate at School of Traffic and Transportation, Beijing Jiaotong University, Beijing, China. Her research interests involve public transit planning and management, transportation simulation, and Intelligent Transportation Systems.

LEI YU, Ph.D., P.E. ( $y$ u_lx@tsu.edu) is Professor and Dean of the College of Science and Technology, Texas Southern University, and a Yangtze River Scholar of Beijing Jiaotong University. He has managed more than 80 research projects and published more than 200 scientific papers.

Xu-Mei Chen, Ph.D. (tcxm@263.net) is Associate Professor at the School of Traffic and Transportation, Beijing Jiaotong University, Beijing, China. Her researches interests involve ITS technologies, urban traffic planning and management, public transit operation, and industry policy of transportation.

Jı-Fu Guo, Ph.D. (Guojf@bjtrc.org.cn) is Director of Beijing Transportation Research Center. His main research areas involve traffic forecasting, metro/highway planning, traffic impact analysis, traffic simulation, and traffic environment analysis. 